\section{FRI0476 ISCHEMIA MODIFIED ALBUMIN IN OSTEOPOROSIS}

ALISIK Tugba ${ }^{1}$, Murat Alisik ${ }^{2}$, Pinar Koyuncu ${ }^{3}$, Baris Nacir ${ }^{1}$, Figen Ayhan ${ }^{1}$ ${ }^{1}$ Ankara Training and Research Hospital, Physical Medicine and Rehabilitation, Ankara, Turkey; ${ }^{2}$ Polatli State Hospital, Medical Biochemistry, Ankara, Turkey; ${ }^{3}$ Ankara Training and Research Hospital, Medical Biochemistry, Ankara, Turkey

Background: Osteoporosis is a common bone metabolism disease, characterized by low bone mass and pathological fractures. This disease is caused by loss of balance in bone resorption and formation. It is thought that this imbalance is associated with increasing in reactive oxygen species (ROS) and/or insufficiency of antioxidant defense (1). ROS adversely affect the formation and life cycle of osteoclasts, osteoblasts and osteocytes (2). Albumin has many functions such as the transport of molecules, the oncotic pressure of plasma and antioxidation. The damage of the ROS to the $\mathrm{N}$-terminal of the albumin reduces the carrying capacity of the albumin and thus the antioxidant capacity. This damage is evaluated by decreasing the cobalt binding capacity of albumin called ischemia modified albumin (IMA), and IMA shows oxidative damage (3).

Objectives: The aim of this study was to determine IMA levels of patient with osteoporosis.

Methods: OP was diagnosed by $t$ score of bone mineral density (BMD). IMA, albumin levels and IMA/Albumin ratio (IMAR) were studied from the sera of patients with osteoporosis (OP) and healthy volunteers (control) (4). Patients who had any chronic disease such as diabetes mellitus, hypertension, and etc. and any acute disease such as infection were excluded from study. Results were shown as mean \pm standard deviation or median (IQR) according to the distribution of variables. $p<0.05$ was considered significant. Results: The study included 28 female patients in OP group and 26 female volunteer in control groups. The mean age was $65.5 \pm 5.4$ and $66.4 \pm 7.4$ for $\mathrm{OP}$ and control groups, respectively ( $p: 0.616)$. Median (IQR) lumbar $t$ scores of $B M D$ of OP group were $-3.1(-3.32 ;-2.85)$. The albumin values of $\mathrm{OP}$ and control groups were $4.38 \pm 0.13$ and $4.40 \pm$ 0.11 , respectively; and no significant difference was found between the groups $(p=0.441)$. The IMA and IMAR results of the OP group were $0.65(0.61 ; 0.74)$ and $0.15(0.14 ; 0.17)$, respectively; and $0.46(0.40$, $0.55)$, and $11(0.09 ; 0.13)$ in the control group, respectively. (Figure 1). Both IMA and IMAR results were significantly lower in the OP group than in the control group (high ABSU) $(p<0.001$; for all).

Conclusion: Cobalt binding capacity of albumin was decreased in patients with osteoporosis. To the best of our knowledge, this study is the first determining IMA levels in osteoporosis. It is known that the cobalt binding capacity of albumin decreased after oxidative damage. It is shown that IMA is increased in some diseases associated with oxidative stress. Similarly, it was showed that thiol-disulphide balance was shifted to disulphide side in postmenopausal osteoporosis and it was an indicator of oxidative stress $(1,2)$. In the light of these results, oxidative stress is thought to play role in the pathophysiology of osteoporosis. As a result, antioxidant replacement such as $\mathrm{N}$-acetyl cysteine, lipoic acid, vitamin $\mathrm{C}$, etc. may be recommended to the patients with osteoporosis.

\section{REFERENCES:}

[1] Altindag O, Erel O, Soran N, Celik H, Selek S. Total oxidative/anti-oxidative status and relation to bone mineral density in osteoporosis. Rheumatology international. 2008;28(4):317-21.

[2] Korkmaz V, Kurdoglu Z, Alisik M, Turgut E, Sezgin OO, Korkmaz H, et al. Thiol/disulfide homeostasis in postmenopausal osteoporosis. Journal of endocrinological investigation. 2017;40(4):431-5.

[3] Ellidag HY, Eren E, Yilmaz N, Cekin Y. Oxidative stress and ischemiamodified albumin in chronic ischemic heart failure. Redox report : communications in free radical research. 2014;19(3):118-23.

[4] Bar-Or D, Lau E, Winkler JV. A novel assay for cobalt-albumin binding and its potential as a marker for myocardial ischemia-a preliminary report. The Journal of emergency medicine. 2000;19(4):311-5.

Disclosure of Interests: None declared

DOI: 10.1136/annrheumdis-2019-eular.8042

FRI0477

STUDY OF CORTICAL AND TRABECULAR COMPARTMENTS THROUGH 3D-SHAPER IN LUNG TRANSPLANTED PATIENTS

Mireia Barceló-Bru ${ }^{1}$, Alba Erra ${ }^{1}$, Carina Espinet ${ }^{2} .{ }^{1}$ Hospital Universitari Vall d'Hebron, Rheumatology, Barcelona, Spain; ${ }^{2}$ Hospital Universitari Vall d'Hebron, Nuclear Medicine, Barcelona, Spain

Background: Osteoporosis in lung transplant (LT) patients is a frequent complication. Glucocorticoid treatment (GC) is a prominent risk factor (RF) that alters both bone mass and architecture. Studying the volumetric BMD using 3D-SHAPER software would help the study of architecture.

Objectives: To study the change in cortical surface density, volumetric trabecular density and integral volumetric density measured by 3DSHAPER before and after LT as well as changes in bone mineral density (BMD) measured by densitometry (DXA).

Methods: LT patients assessed in Rheumatology are included. The demographic characteristics, diagnosis of lung disease and RF of low bone mass prior to LT are collected. Patients were grouped into 3 groups according to the type of disease, these being: Chronic Obstructive Pulmonary Disease (COPD), Interstitial Lung Diseases (ILD) and OTHER pathologies. Bone mass was evaluated by DXA (GE-LUNAR) before and 6 months after LT and 3D-SHAPER software (v2.7, Galgo Medical) was applied in all DXAs.

Results: 49 LT patients were included (46.9\% women), with an average age of $56.9 \pm 8.7$ years. In the ILD group, a higher proportion of patients with a low calcium intake $(p=0.027)$ and with high doses of GC $(p=0.001)$ was observed. COPD group presented the highest proportion of smokers $(p=0.027)$. Prevalence of osteoporosis prior to LT was $24.5 \%$, higher in COPD ( $p=0.007)$. Values of BMD and 3D-SHAPER as well as the percentage of post-transplant variation are shown in Table 1. Of the 47 patients, $19(38.8 \%)$ started osteoactive treatment before LT, with a higher percentage of patients treated in the COPD group ( $p$ $=0.007$ ). Of 42 patients, we have DXA at 6 months post-transplant, with a prevalence of osteoporosis of $23.8 \%$. 27/42 patients underwent posttransplant osteoactive treatment, with an average treatment time until DXA was $19.2 \pm 26.1$ months, with no differences between groups.

Conclusion:

- Prevalence of low bone mass is high both before and after the transplant.

- Prevalence of some osteoporosis RFs was different between the lung disease groups.

- COPD group presented a worse bone mass before LT. Subsequently, they experienced a significant improvement in BMD and volumetric measurements with respect to the other two groups, which showed losses of these parameters. COPD was the group most treated for osteoporosis and with a lower proportion of patients with GC at high doses.

- Trabecular BMDv was the most altered measure of 3D-SHAPER, with greater decrease in patients with GC at high doses and lower in those with osteoactive treatment.

Disclosure of Interests: None declared

DOI: 10.1136/annrheumdis-2019-eular.2429

\begin{tabular}{|c|c|c|c|c|}
\hline PRE-TRASPLANT & $\begin{array}{l}\text { TOTAL } \\
(n=47)\end{array}$ & $\begin{array}{l}\text { COPD } \\
(n=11)\end{array}$ & $\begin{array}{c}\text { ILD } \\
(n=30)\end{array}$ & $\begin{array}{l}\text { OTHERS } \\
(n=8)\end{array}$ \\
\hline $\begin{array}{l}\text { BMD pre-trasplant (mean) } \\
\text {. Lumbar Spine } \\
\text { Femoral Neck } \\
\text {. Total Hip }\end{array}$ & $\begin{array}{c}\mathbf{g} / \mathrm{cm}^{2}(\mathbf{T}- \\
\text { score }) \\
1,074(-1,02) \\
0,868(-1,28) \\
0,907(-1,15)\end{array}$ & $\begin{array}{c}\mathbf{g} / \mathbf{c m}^{2}(\mathbf{T}- \\
\text { score }) \\
0,927^{* *}\left(2,18^{* *}\right) \\
0,798\left(-1,89^{*}\right) \\
0,812^{*}(- \\
\left.2,07^{* *}\right)\end{array}$ & $\begin{array}{c}\mathbf{g} / \mathbf{c m}^{2}(\mathbf{T}- \\
\text { score }) \\
1,131(-0,55) \\
0,899(-1,04) \\
0,950(-0,79)\end{array}$ & $\begin{array}{c}\mathbf{g} / \mathbf{c m}^{2} \mathbf{~ ( T -} \\
\text { score }) \\
1,051(-1,18) \\
0,846(-1,35) \\
0,878(-1,27)\end{array}$ \\
\hline 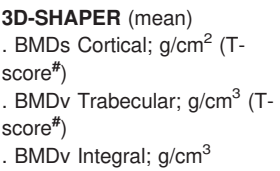 & $\begin{array}{c}155,6(-1,19) \\
146,1(-1,69) \\
296,0\end{array}$ & $\begin{array}{c}143,9\left(-1,90^{*}\right) \\
115,4^{\star \star}(-2,65) \\
258,4^{\star}\end{array}$ & $\begin{array}{c}163,3(-0,97) \\
155,3(-1,64) \\
309,4\end{array}$ & $\begin{array}{c}142,7(-1,26) \\
153,6^{\dagger}(- \\
\left.1,06^{\dagger}\right) \\
297,5\end{array}$ \\
\hline $6 \mathrm{~m}$ POST-TRASPLANT & $\begin{array}{l}\text { TOTAL } \\
(n=42)\end{array}$ & $\begin{array}{l}\text { COPD } \\
(n=10)\end{array}$ & $\begin{array}{c}\text { ILD } \\
(n=25)\end{array}$ & $\begin{array}{c}\text { OTHERS } \\
(n=7)\end{array}$ \\
\hline $\begin{array}{l}\% \text { change BMD }(\text { mean } \pm D E) \\
. \text { Lumbar Spine } \\
. \text { Femoral Neck } \\
\text { Total Hip }\end{array}$ & $\begin{array}{c}-1,26 \pm 10,3 \\
-4,34 \pm 7,3^{\wedge} \\
-3,22 \pm \\
6,0^{\wedge}\end{array}$ & $\begin{array}{c}9,38 \pm 11,6^{* *} \\
-0,74 \pm 6,5 \\
1,18 \pm 3,5^{*}\end{array}$ & $\begin{array}{l}-3,92 \pm 7,3 \\
-5,43 \pm 6,9 \\
-4,07 \pm 6,2\end{array}$ & $\begin{array}{r}-7,03 \pm 7,7^{\dagger} \\
-5,57 \pm 9,3 \\
-6,58 \pm 5,6^{\dagger \dagger}\end{array}$ \\
\hline $\begin{array}{l}\% \text { change 3D-SHAPER } \\
\text { (mean } \pm D E) \\
. \text { BMDs Cortical } \\
\text { BMDv Trabecular } \\
\text {. BMDv Integral }\end{array}$ & $\begin{array}{c}-1,59 \pm 5,9 \\
-4,42 \pm \\
11,6^{\wedge \wedge} \\
-3,11 \pm \\
6,3^{\wedge \wedge}\end{array}$ & $\begin{array}{c}0,14 \pm 4,9 \\
8,63 \pm 8,6^{* *} \\
1,87 \pm 4,3^{*}\end{array}$ & $\begin{array}{l}-2,53 \pm 6,5 \\
-8,12 \pm 9,5 \\
-4,67 \pm 6,5\end{array}$ & $\begin{array}{c}-0,59 \pm 4,9 \\
-11,66 \pm \\
5,1^{\dagger \dagger} \\
-5,20 \pm 3,9^{\dagger}\end{array}$ \\
\hline
\end{tabular}

^ $p<0.05,{ }^{\wedge} p<0.01$ respect previous, ${ }^{*} p<0.05,{ }^{* *} p<0.01$ COPD vs. ILD; ${ }^{\wedge} p<0.05$, ${ }^{\dagger} p<0.01$ COPD vs. OTHERS; \# only in women. 